\title{
Word Pairs Immediate
}

National Cancer Institute

\section{Source}

National Cancer Institute. Word Pairs Immediate. NCI Thesaurus. Code C120332.

A component of the Children's Memory Scale. A child is read a list of paired words and then asked to say the second word after being told the first. The list is presented three times in this fashion. After the third list/cued recall trial the child is asked to tell the examiner as many word pairs as they can with no cues. 